\title{
Use of Hyaluronic Acid (Cystistat) for the Treatment of Late Radiation Induced Cystitis in Patients after Prostate Irradiation
}

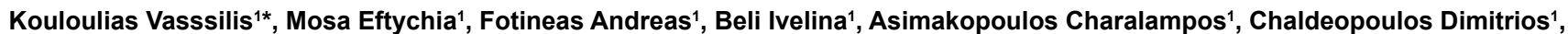
Chrysofos Michael $^{2}$, Siatelis Argyris ${ }^{2}$ and Kelekis Nikolaos ${ }^{1}$

${ }^{1}$ Department of Radiology, Radiotherapy Unit, ATTIKON University Hospital, Xaidari, Greece

${ }^{2}$ Urology Clinic, ATTIKON University Hospital, Xaidari, Greece

\begin{abstract}
Purpose: To evaluate the efficacy, feasibility as well as the safety of the hyaluronic acid (CYSTISTAT), as an intravesical treatment for the radiation induced cystitis.

Materials and Methods: Between September 2009 and December 2012, in a prospective way, 20 patients with prostate cancer that had showed radiation induced cystitis after radiotherapy, were selected for the present analysis and were treated with intravesical instillations of CYSTISTAT. All candidates had undergone three-dimensional confomal radiotherapy with a total dose of 72-74 Gy. They all suffered from radiation induced cystitis and painfull bladder syndrome and treated with 4 weekly bladder instillations of CYSTISTAT and 2 monthly instillations thereafter. Patients were started to be clinically evaluated 6 months post radiotherapy. Symptoms of haematuria, frequency of voiding and findings from cystoscopy were assessed before and 3 months after CYSTISTAT treatment, according the EORTC/RTOG criteria.

Results: The median age was 66 years. Treatment response was evaluated up to 20 months post radiotherapy. The patients were undergone cystoscopy before and after the CYSTISTAT treatment. All candidates completed the treatment scheme and no serious side effects of intravesical instillation of CYSTISTAT were recorded. A significant reduce of radiation induced cystitis was noted, since the mean score of radio-cystitis before and after the CYSTISTAT instillation was $2.70 \pm 0.47$ and $1.45 \pm 0.51$, respectively $(P<0.01$, Wilcoxon test). None of the patients presented any severe event during or after the CYSTISTAT instillation.
\end{abstract}

Conclusions: CYSTISTAT is a well-tolerated modality which achieves a significant decrease of bladder bleeding, pelvic pain and frequency of voiding

Keywords: Hyaluronic acid; Radiation-induced cystitis, Painful bladder syndrome

\section{Introduction}

Radiation induced cystitis is a severe complication of highdose radiotherapy when administered as the treatment of pelvic malignancies. It is a rare bladder disease that occurs in 3-6\% of patients [1]. As a condition, can be the result of a wide variety of causative factors. Microscopically, it is characterized of a primary defect in the glycosaminoglycan (GAG) layer of the bladder mucosa [2,3].

Normally, the mucous coat of the bladder urothelium protects the bladder wall from injury due to microorganisms, toxic molecules and ions. It has been suggested that a defect of the GAGs, permits the access of the irritating components of the urine to the epithelium, leading to the characteristic symptoms of interstitial cystitis [4].

According to the EORTC/RTOG toxicity criteria, the symptoms of cystitis vary from minor telangiectasia which causes microscopic hematuria, to severe frequency and dysuria, frequent hematuria and reduction of the bladder capacity in less than $150 \mathrm{cc}$ of urine [5].

Many studies have as a purpose to repair the damage bladder layer using a variety of modalities, like hyperbaric oxygen, oral pentosanpolysulfate (Elmiron), evendimethyl sulfoxide (DMSO), heparin and even surgical interventions [6].

Hyperbaric oxygen has been used successfully as an effective therapy in treatment-resistant radiogenic cystitis for the last 15 years [7]. This therapeutic modality is based on the administration of $100 \%$ oxygen in a hyperbaric chamber at a pressure of $2.5 \mathrm{~atm}$ absolute, for at least 60 minutes daily, seven days a week, for a minimum time of a month [8].

Oral pentosanpolysulfate was another therapeutic option with intense of restoring GAG layer. According to Fritjofsson et al. [9], this regimen showed a good effect in non-ulcer type cystitis. The use of dimethyl sulfoxide (DMSO) has been used effectively against many of cystitis' symptoms [10]. Other current therapies include oral treatment choices as Elmiron, heparin, or even surgical interventions The aim of our study is to investigate the potential efficacy together with safety, of intravessical instillations of hyaluronic acid, in patients that suffer from radiation induced cystitis after a high-dose radiotherapy regimen. We reported our experience and we suggest it as an alternative way of treating interstitial cystitis.

*Corresponding author: V Kouloulias, Department Radiology, Radiotherapy Unit, Medical School of Athens, ATTIKON University Hospital, Greece, Tel: 00302107286319; Fax: +302105326418; E-mail: vkouloul@ece.ntua.gr

Received November 04, 2013; Accepted January 24, 2014; Published January 31,2014

Citation: Vasssilis $\mathrm{K}$, Eftychia M, Andreas F, Ivelina B, Charalampos A, et al. (2014) Use of Hyaluronic Acid (Cystistat) for the Treatment of Late Radiation Induced Cystitis in Patients after Prostate Irradiation. J Bioequiv Availab 6: 018-022. doi:10.4172/jbb.1000174

Copyright: (c) 2014 Vasssilis K, et al. This is an open-access article distributed under the terms of the Creative Commons Attribution License, which permits unrestricted use, distribution, and reproduction in any medium, provided the original author and source are credited. 
Citation: Vasssilis K, Eftychia M, Andreas F, Ivelina B, Charalampos A, et al. (2014) Use of Hyaluronic Acid (Cystistat) for the Treatment of Late Radiation Induced Cystitis in Patients after Prostate Irradiation. J Bioequiv Availab 6: 018-022. doi:10.4172/jbb.1000174

\section{Materials and Methods}

\section{Patient characteristics}

In a prospective way, clinical data of 20 patients treated at University Hospital of Athens, Attikon between September 2009 and December 2012, who were presented with radiation induced cystitis after prostate irradiation, were collected. All candidates were men with a median age of 66 years. The patients' characteristics are shown in Table 1.

The pretreatment evaluation before radiotherapy included medical history, physical examination, blood profile (including Complete Blood Count, PSA determination, liver function tests, testosterone measurement) and staging exams as CT and MRI of the pelvis. Eligible patients for radiotherapy had histologically confirmed clinical Prostate Cancer Stage T2 (according to American Joint Committee on Cancer staging manual, 7th edition, 2010), Gleason score $\geq 7$ and prostatespecific antigen (PSA) levels more than $10 \mathrm{ng} / \mathrm{mL}$. All patients were medically inoperable for radical prostatectomy due to co-morbidities (cardiac surgery or stent after cardiac mal-function, chronic obstructive lung disease, etc). The co-morbidities in details are shown in Table 1.

All patients included in the present analysis had to suffer from grade II-III radiation cystitis as a late morbidity (6-9 months post irradiation).None of the candidates had Hunner's ulcer at cystoscopy and all of them had sterile urine at the initiation of the Cystistat therapy. The median time from the finalization of radiotherapy until the presentation of cystitis was 9.5 months (range 6-14).

Patients were excluded from the study if they had received another medical or mechanical treatment for cystitis apart from painkillers, a month before the screening, if they suffered from bladder cancer too, and if they had a known sensitivity to any of Cystistat's components.

All men were required to sign an informed consent form previously, concerning the side effects of the Cystistat's instillations.

\section{Radiotherapy technique}

In the past, each of the patient that suffered from radiation-induced cystitis, had underwent a virtual CT-simulation, in supine position, using "knee sponge" to consistently align thighs, for treatment planning purposes $[11,12]$. Patients had been instructed to have a full bladder

\begin{tabular}{ll}
\hline Median Age (range) & $\mathbf{( 6 6 )}$ \\
\hline Stage & 11 \\
T2a & 3 \\
T2b & 5 \\
T2c & \\
\hline Total dose & 6 \\
72Gy & 14 \\
$74 G y$ & $16.7(10.1-35)$ \\
\hline Mean PSA (range) & 15 \\
\hline DRE findings & 5 \\
One lobe & \\
Both lobes & 2 \\
\hline Co-morbidities & 3 \\
Cardiac surgery & 6 \\
Arterial stent & 5 \\
Chronic obstructive lung disease & 4 \\
Hypertension & \\
Diabetes &
\end{tabular}

Table 1: Patients characteristics. and empty rectum (following a dietary suggestion) during simulation and the whole course of treatment.

The CT scan covering a region from the first lumbar vertebra to the lower part of the perineum had been obtained for each patient. A conventional virtual CT simulation before CT scan had been performed to define preliminary isocenter and beam width.

All contouring of target volumes and normal structures (organs at risk-OARs) had been performed in the Prosoma Treatment Planning System. Magnetic resonance and computed tomography images had been obtained at 3-mm intervals. The CT and MRI had been registered by the Prosoma system while corrections had been made in the CTbased contouring of the prostate by taking into account the MRI images. The following structures had been delineated: CTV, PTV according to the ICRU criteria [12-14].

The CTV was the prostatic gland and the seminal vesicles; the PTV was obtained by expanding CTV with a margin of $1 \mathrm{~cm}$ in each direction, and of $0.7 \mathrm{~cm}$ posteriorly. The CTV, PTV and OARs were outlined on all CT slices [15-17]. None of the patients received pelvic node irradiation.

The prescription dose of 72-74 Gy had been defined for the 95\% isodoses of the PTV. Beams had been conformally shaped around the PTV and partial wedging or dynamic Multi Leaf Collimator (MLC) had been employed to improve dose homogeneity. To evaluate the dose constraints for normal tissues we had used the NCCN 2010 guidelines (http://www.nccn.org/), the Radiation Oncology Group (RTOG) GU consensus as reported by Lawton et al. and the QUANTEC report $[18,19]$.

The dose constraints for the OARs are described below:

1. Bladder: V $75<25 \%$, V $70<35 \%$, V $65<50 \%$.

2. Rectum: V75 <15\%, V70 <20\%, V65 <25\%, V60 <35\%, V50 $<50 \%$.

3. Femoral heads: V50 $<5 \%$.

4. Small bowel: $\mathrm{V} 52=0 \%$.

5. Penile bulb: Mean dose $<50 \mathrm{~Gy}$

The PTV had been treated, using a four field technique [20,21]. The total prescribed dose of 72-74 Gy had been delivered in 36-37 daily fractions (Monday to Friday) to the whole prostatic gland, given in 2 Gy fractions. Treatments have been delivered with $15 \mathrm{MV}$ photon beam generated by a Clinac $2100 \mathrm{C}$ Varian accelerator.

\section{Clinical examination}

During the radiation treatment the patients were monitored every week with clinical examination. After the completion of the treatment, the patients were evaluated by a radiation oncologist every three months for a 24 months period of time. Data at diagnosis (baseline) of radiation cystitis and at 3-months post cystistat injection have been analyzed in this report. A cystoscopy was performed before cystistat and three months thereafter, by two different urologists. The radiation induced bladder toxicity was analysed by using the RTOG/EORTC late toxicity criteria for the bladder [5]. Symptoms occurring in the follow-up period before and after the cystistat injection were classified as "late". 
Citation: Vasssilis K, Eftychia M, Andreas F, Ivelina B, Charalampos A, et al. (2014) Use of Hyaluronic Acid (Cystistat) for the Treatment of Late Radiation Induced Cystitis in Patients after Prostate Irradiation. J Bioequiv Availab 6: 018-022. doi:10.4172/jbb.1000174

\section{Cystistat injection}

1. In the present study, all the candidates that presented with radiation-induced cystitis underwent intravesical instillations of hyaluronic acid (Cystistat) at a dose of $40 \mathrm{mg}$ in a volume of $50 \mathrm{ml}$ of phosphate-buffered saline. The instillations were performed by a radiation oncologist and an urologist in the outpatients clinic of our department. The whole procedure was performed using a sterile catheter, after the removal of the residual urine. Following the instillation, the patients had to remain at bed, retaining the hyaluronic acid in their bladders for at least one hour thereafter.

2. Cystistat was administered once a week for 4 weeks and then once a month for the following two months, for a total three months period. A cystoscopy was performed three months after the completion of the instillations.

\section{Endpoints}

Endpoints included treatment feasibility and efficacy. Treatment feasibility was defined as the successful delivery of the instillations following the intended treatment schedule. Efficacy was based on the rate of local recurrence.

Radiation Induced Cystitis was grading according to EORTC/ RTOG toxicity criteria [5]. All patients completed questionnaires forms, from which they were assessed subjective characteristics like pain, included in the evaluation of the EORTC/RTOG score.

\section{Statistical analysis}

The comparison for morbitiy scores before and after the cystistat injection was performed with the Wilcoxon non-parametric test. The incidence of radiation-cystitis before and after the cystistat injection was analyzed with the chi $^{2}$ test. The significance level was set at the level of 0.05 . All the statistical test and the descriptive statistics were performed with the SPSS ver 10 software (IL, USA).

\section{Results}

All patients had good performance status according to Eastern Cooperative Oncology Group performance score of $0-1$. The median age was 66 years. Median follow-up duration was 12 months post radiotherapy (range, 9-18 months).

A significant reduction of radiation induced cystitis was noted after the instillation of cystistat, as shown in Table $2\left(\mathrm{Chi}^{2}<0.01\right)$. More specifically, before hyaluronic acid instillations $70 \%$ of the patients suffered from grade III cystitis, with severe frequency and dysuria, severe generalized telangiectasia, frequent hematuria and symptoms of reduction of the bladder capacity. The remaining $30 \%$ of the patients showed grade II bladder toxicity, with moderate frequency, generalized telangiectasia and intermittent macroscopic hematuria. After the therapeutic scheme with the Cystistat instillations, the cystoscopy revealed $45 \%$ of the men with only grade I bladder toxicity, with slight epithelial atrophy and minor telangiectasia, and 55\% with grade II toxicity. None of the patients showed grade III remaining bladder toxicity. As shown in Figure 1, the mean score of radio-cystitis before and after the cystistat instillation was $2.70 \pm 0.47$ and $1.45 \pm$ 0.51 , respectively $(\mathrm{P}<0.01$, Wilcoxon test). In Figure 2 , a cystoscopy is shown for a patient before (Figure 2a) and after (Figure 2b) the cystistat instillations. The typical grade III hemorrhagic interstitial cystitis has been reduced in a grade II non-hemorragic one but with signs of telangiectasia (irradiated vessels). None of the patients presented any severe event during or after the cystistat instillation. Only two patients complained for a discomfort during the catheterization. The urinary tract infection (UTI) rate was minimal, since none of our patients had any symptoms of sepsis from the repeated catheterizations.

\section{Discussion}

Radiation-induced cystitis is a major challenge because of its unknown etiology. Many therapeutic attempts have been made based either on empirical grounds or on theoretical speculations about possible etiologies. The tailoring of the irradiation field and the limiting of the radiation dose to the bladder has been proposed in order to reduce the incidence of interstitial cystitis. Various oral agents have been used, such as steroids, vitamin $\mathrm{E}$ and orgotein with

\begin{tabular}{|l|l|l|l|}
\hline Grade & $\begin{array}{l}\text { Description (EORTC/RTOG criteria) } \\
\text { I }\end{array}$ & $\begin{array}{l}\text { Before } \\
\text { instillation }\end{array}$ & $\begin{array}{l}\text { 3 months after } \\
\text { instillation }\end{array}$ \\
\hline II & $\begin{array}{l}\text { Sight epithelial atrophy } \\
\text { hematuria) }\end{array}$ & $9 / 20(45 \%)$ \\
\hline III & $\begin{array}{l}\text { Moderate frequency } \\
\text { Generalized telangiectasia } \\
\text { Intermittent macroscopic hematuria }\end{array}$ & $6 / 20(30 \%)$ & $11 / 20(55 \%)$ \\
\hline $\begin{array}{l}\text { Severe frequency and dysuria } \\
\text { Severe generalized telangiectasia } \\
\text { (often with petechiae) } \\
\text { Frequent hematuria } \\
\text { Reduction in bladder capacity }(<150 \\
\text { cc) }\end{array}$ & $14 / 20(70 \%)$ & - \\
\hline
\end{tabular}

Table 2: EORTC/RTOG radiation induced cystitis as late toxicity, before and afte cystistat instillation $\left(\mathrm{chi}^{2}<0.01\right)$

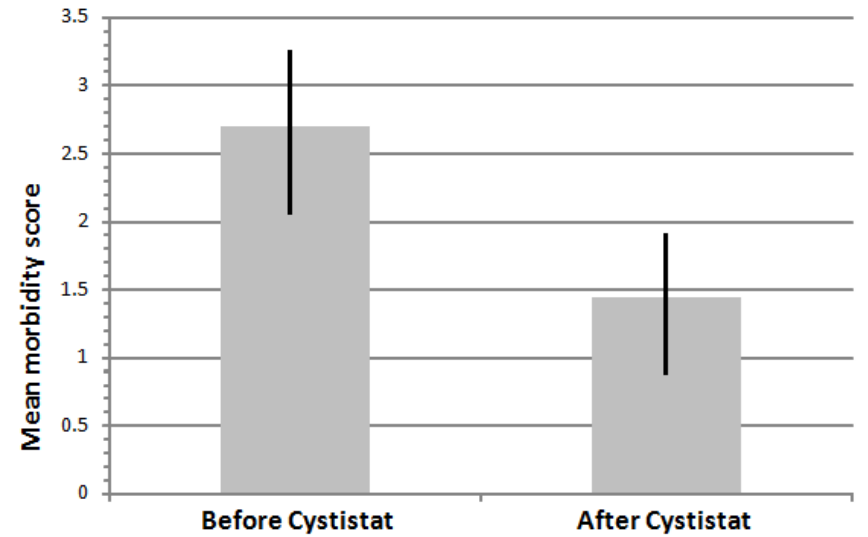

Figure 1: Mean score of radiation induced cystitis before and after cystistat instillation $(P<0.01$, Wilcoxon test). The vertical bars stand for standard deviation (SD).

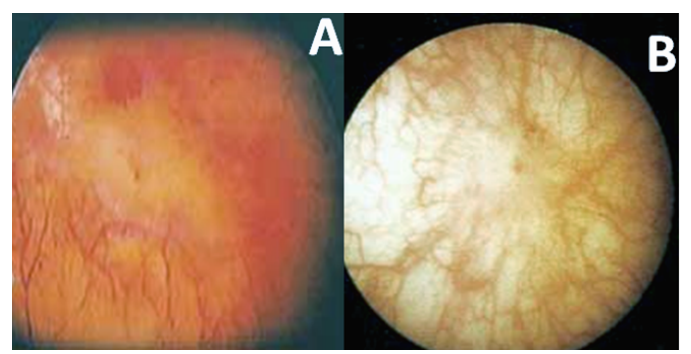

Figure 2: Cystoscopy before (A) and after (B) cystistat instillation. 
Citation: Vasssilis K, Eftychia M, Andreas F, Ivelina B, Charalampos A, et al. (2014) Use of Hyaluronic Acid (Cystistat) for the Treatment of Late Radiation Induced Cystitis in Patients after Prostate Irradiation. J Bioequiv Availab 6: 018-022. doi:10.4172/jbb.1000174

no success. Elmiron (pentose polysulfate sodium) is the only approved oral treatment for the interstitial cystitis, but the optimal dose has not yet been administered. Intravesical instillations of bacillus CalmetteGuerin have shown good results in some symptoms, but its use is controversial [10]. Another intravesical therapy which is based on the instillation of dimethyl sulfoxide (DMSO) is effective in the treatment of many symptoms, but the fact that is a potent organic solvent, raise concerns for its long-term use. Additionally its unpleasant persistent garlic smell makes it unpopular, as an option [10].

On the one hand the use of hyperbaric oxygen in patients with radiation induced cystitis is an adequate therapeutic option. It has shown remarkable response rates and reduction of gross hematuria and pelvic pain [8]. However the high cost of the treatment and the lack of the hardware make this treatment option difficult to be administered.

On the other hand, there is the intravessical instillation with Cystistat. It is known that hyaluronic acid is a major mucopolysaccharide in the connective, epithelial and neural tissues and stands for one of the main components of the extracellular matrix that contributes significantly to cell proliferation and migration. Additionally play the role of a protective barrier against irritating agents that can potentially cause damage to the epithelium [22]. Hyaluronic acid may inhibit immune complexes, leucocyte migration, may promote regulation of the fibroblasts, endothelial cell proliferation and enhancement of the healing tissues. A damage of the glycosaminoglycan layer (GAG) may lead to direct exposure to components of urine, to fungus and bacterium. This damage can lead to interstitial cystitis and subsequently can be treated by Cystistat.

Morales et al. [23] demonstrated that $71 \%$ of the patients that underwent therapy based on hyaluronic acid instillations, showed an improvement of their symptoms, revealing the direct relation between GAG, hyaluronic acid and the controlling of the interstitial cystitis. These results are in accordance with those of our study. More specifically, in our trial, three months after the completion of the instillations all of the patients showed remarkable response. Although at the beginning of the study, $70 \%$ of the men had grade III cystitis, at the second cystoscopy there was no patient with grade III bladder toxicity. Additionally, $45 \%$ of the patients manage to have only grade I atrophy, while the rest $55 \%$ presented with grade II.

Miodosky et al. [22] resulted that hyaluronic acid instillations can show immediate benefit in releasing the macroscopic hematuria, pain and frequency of voiding. Also have shown the satisfactory effective duration of the treatment. Similarly, our statistical analysis gave well promising results, since according to Figure 1, the mean score of radiocystitis before and after the cystistat instillations was $2.70 \pm 0.47$ and $1.45 \pm 0.51$, respectively $(\mathrm{P}<0.01$, Wilcoxon test $)$.

Nevertheless, there are few side effects from the hyaluronic acid instillations that are caused by the repeated urethral catheterization and lead to urinary infections, but this incidence has not significant difference with those of the use of hyperbaric acid [8].

Data from Kallestrup et al. [24] trial showed that hyaluronic acid reduces pain associated with interstitial cystitis, day-time frequency and nocturia for at least a period of 3 years. Considering the efficacy of the hyaluronic acid instillations and the lack of systemic side-effects, this study similarly with our own one, recommend the treatment of Cystistat in radiation-induced cystitis.

Another trial published by Sommariva et al. [25] demonstrated that intravesical instillation with sodium hyaluronate seem to be a valid and quick therapeutic solution for iatrogenic cystitis from chemotherapy or radiotherapy.

\section{Conclusions}

Our study showed that instillation with Cystistat is a feasible and safe modality to treat patients with radiation induced cystitis. However, the study had two main weaknesses. On the one hand the evaluation for the radio-cystitis was not blind. On the other hand, we had no evidence of the damaged surface glycosaminoglycan layer due to the interstitial cystitis. Thus for future trials the biopsy for the potential cohesive or thicker would go a long way to supporting the role of cystistat for radiation induced cystitis. The encouraging treatment results have confirmed the clinical value of hyaluronic acid in those patients and can be recommended as a treatment option, while a prospective randomized study stands in need for the confirmation of our results.

\section{References}

1. Degener S, Strelow H, Pohle A, Lazica DA, Windolf J, et al. (2012) [Hyperbaric oxygen in the treatment of hemorrhagic radiogenic cystitis after prostate cancer]. Urologe A 51: 1735-1740.

2. Parsons CL (2002) Interstitial cystitis: epidemiology and clinical presentation. Clin Obstet Gynecol 45: 242-249.

3. Daha LK, Riedl CR, Hohlbrugger G, Knoll M, Engelhardt PF, et al. (2003) Comparative assessment of maximal bladder capacity, $0.9 \% \mathrm{NaCl}$ versus 0.2 $\mathrm{M} \mathrm{Kcl}$, for the diagnosis of interstitial cystitis: a prospective controlled study. J Urol 170: 807-809.

4. Ruggieri MR, Chelsky MJ, Rosen SI, Shickley TJ, Hanno PM (1994) Current findings and future research avenues in the study of interstitial cystitis. Urol Clin North Am 21: 163-176.

5. Cox JD, Stetz J, Pajak TF (1995) Toxicity criteria of the Radiation Therapy Oncology Group (RTOG) and the European Organization for Research and Treatment of Cancer (EORTC) Int J Radiat Oncol Biol Phys 31: 1341-1346.

6. Moldwin RM, Sant GR (2002) Interstitial cystitis: a pathophysiology and treatment update. Clin Obstet Gynecol 45: 259-272.

7. Duggan B, Nambirajan T, Johnston SR (2003) Re: Crew JP, Jephcott CR Reynard JM. Radiation-induced haemorrhagic cystitis. EurUrol 2001;40(2):11123. Eur Urol 43: 323

8. Shao Y, Lu GL, Shen ZJ (2012) Comparison of intravesical hyaluronic acid instillation and hyperbaric oxygen in the treatment of radiation-induced hemorrhagic cystitis. BJU Int 109: 691-694.

9. Fritjofsson A, Fall M, Juhlin R, Persson BE, Ruutu M (1987) Treatment of ulcer and nonulcer interstitial cystitis with sodium pentosanpolysulfate: a multicenter trial. J Urol 138: 508-512.

10. Peeker R, Haghsheno MA, Holmang S, Fall M (2000) Intravesical bacillus Calmette-Guerin and dimethyl sulfoxide for treatment of classic and nonulcer interstitial cystitis: a prospective, randomized double-blind study. J Urol 164 1912-1915.

11. Bayley AJ, Catton CN, Haycocks T, Kelly V, Alasti H, et al. (2004) A randomized trial of supine vs. prone positioning in patients undergoing escalated dose conformal radiotherapy for prostate cancer. Radiother Oncol 70: 37-44.

12. Fiorino C, Reni M, Bolognesi A, Bonini A, Cattaneo GM, et al. (1998) Set-up error in supine-positioned patients immobilized with two different modalities during conformal radiotherapy of prostate cancer. Radiother Oncol 49: 133141.

13. International Commission on Radiation Units and Measurements II (1993) Prescribing, Recording, and Reporting Photon Beam Therapy (Report 50).

14. International Commission on Radiation Units and Measurements II (1999) Prescribing, Recording and Reporting Photon Beam Therapy (Supplement to ICRU Report 50), ICRU Report 62.

15. Kantzou I PK, Sandilos P, Gouliamos A, Kouvaris I, Sarris G, et al. (2011) Conventional versus virtual simulation for radiation treatment planning of prostate cancer: final results. J Buon P 309-315. 
Citation: Vasssilis K, Eftychia M, Andreas F, Ivelina B, Charalampos A, et al. (2014) Use of Hyaluronic Acid (Cystistat) for the Treatment of Late Radiation Induced Cystitis in Patients after Prostate Irradiation. J Bioequiv Availab 6: 018-022. doi:10.4172/jbb.1000174

16. Kitamura K, Shirato H, Seppenwoolde Y, Onimaru R, Oda M, et al. (2002) Three-dimensional intrafractional movement of prostate measured during realtime tumor-tracking radiotherapy in supine and prone treatment positions. Int $\mathrm{J}$ Radiat Oncol Biol Phys 53: 1117-1123.

17. Nederveen AJ, van der Heide UA, Dehnad H, van Moorselaar RJ, Hofman $P$, et al. (2002) Measurements and clinical consequences of prostate motion during a radiotherapy fraction. Int J Radiat Oncol Biol Phys 53: 206-214.

18. van Herk M, Remeijer P, Rasch C, Lebesque JV (2000) The probability of correct target dosage: dose-population histograms for deriving treatment margins in radiotherapy. Int J Radiat Oncol Biol Phys 47: 1121-1135.

19. Bentzen SM, Constine LS, Deasy JO, Eisbruch A, Jackson A, et al. (2010) Quantitative Analyses of Normal Tissue Effects in the Clinic (QUANTEC): An Introduction to the Scientific Issues. Int J Radiat Oncol Biol Phys 76: S3-S9.

20. Lawton CA, Michalski J, El-Naqa I, Buyyounouski MK, Lee WR, et al. (2009) RTOG GU Radiation oncology specialists reach consensus on pelvic lymph node volumes for high-risk prostate cancer. Int J Radiat Oncol Biol Phys 74 383-387.

21. Bedford JL, Khoo VS, Oldham M, Dearnaley DP, Webb S (1999) A comparison of coplanar four-field techniques for conformal radiotherapy of the prostate. Radiother Oncol 51: 225-235.

22. Miodosky M, Abdul-Hai A, Tsirigotis P, Or R, Bitan M, et al. (2006) Treatment of post-hematopoietic stem cell transplantation hemorrhagic cystitis with intravesicular sodium hyaluronate. Bone Marrow Transplant 38: 507-511.

23. Morales A, Emerson L, Nickel JC (1997) Intravesical hyaluronic acid in the treatment of refractory interstitial cystitis. Urology 49: 111-113.

24. Kallestrup EB, Jorgensen SS, Nordling J, Hald T (2005) Treatment of interstitial cystitis with Cystistat: a hyaluronic acid product. Scand J Urol Nephrol 39: 143147.

25. Sommariva ML, Sandri SD, Ceriani V (2010) Efficacy of sodium hyaluronate in the management of chemical and radiation cystitis. Minerva Urol Nefrol 62: 145-150. 